\title{
Heavy isotope production by nuclear devices
}

\author{
Facsimile Price $\$$ \\ Microfilm Price \$ \\ Available from the \\ Office of Technical Services \\ Department of Commerce \\ Washington 25, D. C.
}

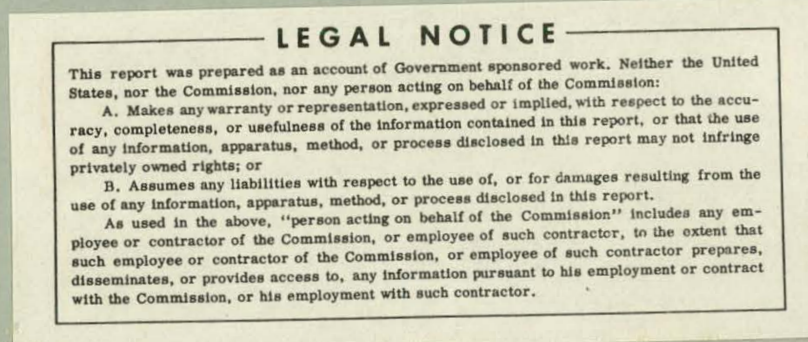

third plowshare, symposium
engine ering with
nuclear explosives

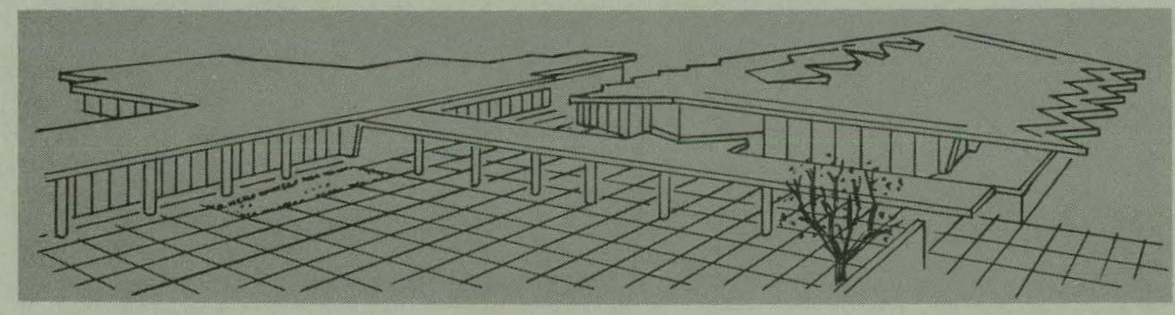

\section{f $r$ e bor $n$ h a I I}

university of california, DAVIS april21-22-23, 1964 


\section{DISCLAIMER}

This report was prepared as an account of work sponsored by an agency of the United States Government. Neither the United States Government nor any agency Thereof, nor any of their employees, makes any warranty, express or implied, or assumes any legal liability or responsibility for the accuracy, completeness, or usefulness of any information, apparatus, product, or process disclosed, or represents that its use would not infringe privately owned rights. Reference herein to any specific commercial product, process, or service by trade name, trademark, manufacturer, or otherwise does not necessarily constitute or imply its endorsement, recommendation, or favoring by the United States Government or any agency thereof. The views and opinions of authors expressed herein do not necessarily state or reflect those of the United States Government or any agency thereof. 


\section{DISCLAIMER}

Portions of this document may be illegible in electronic image products. Images are produced from the best available original document. 
HEAVY ISOTOPE PRODUCTION BY NUCLEAR DEVICES

D. W. Dorn

Lawrence Radiation Laboratory, University of California

Livermore, California

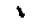

0

$-i-$ 
BIOGRAPHICAL SKETCH OF AUTHOR

David William Dorn was born in

IIis

undergraduate work was done at Purdue University from which he was granted the B. Sc. degree (physics) in 1952. He subsequently served with the United Nation's Forces in Korea until 1955. After release from the Navy, he returned to Purdue and completed his work for the $\mathrm{PhD}$ in 1959. Since graduation, he has been with the Lawrence Radiation Laboratory, Livermore. 


\begin{tabular}{|c|c|c|c|c|}
\hline \multicolumn{5}{|c|}{ ABSTRACT } \\
\hline $\begin{array}{l}\quad \text { Sinc } \\
\text { interest ir } \\
\text { sures, gr } \\
\text { could bene } \\
\text { nuclear st } \\
\text { bility tren } \\
\text { Mike, the } \\
\text { figure of } r \\
\text { produced } \\
\text { This ratio }\end{array}$ & $\begin{array}{l}\text { e } 1952 \text { therr } \\
\text { e of nuclear } \\
y \text { in excess } \\
\text { from these } \\
\text { ture of the v } \\
\text { in the heavy } \\
\text { lave been for } \\
\text { it for these } \\
\text { mass numb } \\
\text { depends se }\end{array}$ & $\begin{array}{l}\text { onuclea: } \\
\text { xplosiv } \\
\text { those a } \\
\text { ossly ir } \\
\text { ry heav } \\
\text { uclei, a } \\
\text { succes } \\
\text { ots is } t \\
\text { requal } \\
\text { sitively }\end{array}$ & $\begin{array}{l}\text { etonation, " } \mathrm{l} \\
\text { to achieve ver } \\
\text { ilable from re } \\
\text { eased fluxes a } \\
\text { lements, fiss } \\
\text { chemistry of } \\
1 \text { experiments } \\
\text { ratio of the a } \\
246 \text { to that of } \\
\text { the thermal }\end{array}$ & $\begin{array}{l}\text { ike," there has been } \\
\text { y high neutron expo- } \\
\text { actors. Fields which } \\
\text { re: nucleogenesis, } \\
\text { on processes, sta- } \\
\text { hew elements. Countin } \\
\text { in this field. A } \\
\text { nount of elements } \\
\text { nass number } 245 \text {. } \\
\text { lux achieved. }\end{array}$ \\
\hline Shot & $\begin{array}{l}\text { Sponsoring } \\
\text { Laboratory }\end{array}$ & Date & $R \equiv \frac{A=246}{A=245}$ & $\begin{array}{l}\text { Implied thermal flux } \\
\left(\text { moles } \mathrm{n} / \mathrm{cm}^{2}\right)\end{array}$ \\
\hline Mike & LASI & $11 / 52$ & 0.38 & 2.0 \\
\hline Anacostia & $\mathrm{LRL}$ & $11 / 62$ & 0.48 & 2.5 \\
\hline Kennebec & LRL & $6 / 63$ & 0.69 & 4.7 \\
\hline Anchovy & LASL & $11 / 63$ & 0.4 & 2.0 \\
\hline
\end{tabular}

Since Mike, all experiments have used devices of low yield which can be readily contained underground. Conceptual designs now exist which should be able to give considerably higher neutron exposures. 


\title{
HEAVY ISOTOPE PRODUCTION BY NUCLEAR DEVICES
}

\author{
D. W. Dorn
}

In November 1952 an event took place which was to have a profound effect on political alignments of the world. This event was the detonation of "Mike," the first large thermonuclear device. The political implications of this experiment overshadowed what, to many of us, has come to be a major advance in the development of scientific tools. By this I mean the experimentally verified, extremely high thermal neutron flux observed in Mike. Subsequent to this observation, the Atomic Energy Commission established a study program to investigate this particular characteristic of nuclear devices. Under the program, Los Alamos Scientific Laboratory and Lawrence Radiation Laboratory, Livermore, have studied the mechanisms of high fluxes, capture systematics, general slability characteristics, and more specifically, nuclear design to accomplish this massive neutron irradiation.

Utilization of these grossly increased fluxes can be expected to significantly advance understanding in many fields. For instance, in cosmology, the study of nucleogenesis has always been difficult because of the lack of controlled experimental techniques of investigation. With the advent of these high-flux "machines" it will now be possible to simulate the supernova $R$ process (neutron capture on a rapid time scale) and to study relative abundances of highly neutron-rich nuclides. This will cast light on naturally occurring processes and will assist in interpreting naturally occurring mass ratios. Also, in the study of nuclear structure, branching ratios for the various modes of decay (alpha, beta, and spontaneous fission) give important information on the influence of single-particle structure on energy levels of these complex nuclei. 
Johansson ${ }^{1}$ and Zamick ${ }^{2}$ have had some success in attributing nuclear properties, in the region of uranium and beyond, to specific shell model configurations. In addition, Perlman ${ }^{3}$ has suggested that the short time scale involved in these capture processes may "freeze in" high spin states. That is, successive capture of neutrons may synthesize metastable states of high angular momentum.

Another use of this high flux is the synthesis of samples of spontaneously fissioning odd-A (non-zero spin) nuclei. Observation of the angular correlation of fission products will give information on shapes of nuclei at or near scission (the moment of actual fission), and will contribute to our knowledge of the fission processes. Understanding stability trends of these superheavy nuclei has also proven to be an extremely difficult problem. Foreman and Seaborg ${ }^{4}$ observed a correlation of the drop in spontaneous fission lifetimes with the minor shell of 152 neutrons (Fig. 1). Other investigators ${ }^{1,5-12}$ have considered this and other problems of these nuclei. Werner and Wheeler, ${ }^{12}$ for example, have treated general stability characteristics of superheavy nuclei (Fig. 2). Conclusions reached in that work may be modified by. compositiondependent terms as pointed out by Brandt, et al. ${ }^{13}$ Difficulties in extrapolations like these are demonstrated by Fig. 3 which shows the unphysical precipitous drop ${ }^{14}$ of the spontaneous fission lifetimes of uranium isotopes with increasing $A$. Investigation of stability trends using nuclear devices can be expected to differentiate between the presently existing theories and to stimulate new ideas. Mass formulas have been developed by many people, ${ }^{15-18}$ but here again, the range of validity should probably be restricted to near the known nuclei. Extension of the data will contribute significantly to our knowledge and understanding of the mass surface. Finally, the chemistry of these new elements is extremely interesting. Lawrencium is thought to be the last member of the actinide series; therefore, it is important to verify the predicted different chemical properties of elements 104 and beyond. 
Comparing the relative neutron flux in Mike and in, for example, the HFIR (high flux isotope reactor at Oak Ridge), shows that, on a consistent model, Mike calculates to have given about 2 moles of neutrons per square $\mathrm{cm}$ (Fig. 4), while a full year irradiation in the HFIR gives about 0.15 mole per square $\mathrm{cm}$. In addition, if a typical capture path for a reactor passes through a nuclide with either a high destruction cross section or a short spontaneous fission half-life, further irradiation of the sample may prove fruitless. An example of this is the high losses occurring in reactors at cialifornium 254. This set of problems is exchanged for an unknown but presumably different set when we use a nuclear device (the new problems include mainly the question of the systematics of capture and destruction cross sections, and decay rates for increasing mass number of the same element). Figure 5 contrasts the capture paths followed in a reactor with those in a nuclear device.

There have been four successful experiments in the Atomic Energy Commission's heavy.element program. In evaluating these, a useful figure of merit is furnished by the ratio of the total amount of elements produced with mass number equal to 246 to that of mass number 245 . Since these mass numbers consist mainly of plutonium and americium isotopes, their radiochemical detection is straightforward, and a high degree of confidence can be placed in the ratio. To obtain the thermal flux implied by this ratio, we can either calculate explicitly, as in Ref. 13, or make an approximate analytic calculation as follows:

$$
R \equiv \frac{N^{246}}{N^{245}}=\frac{2\left(1-e^{-2 \sigma \phi}\right)-4 \sigma \phi e^{-\sigma \phi}}{1+e^{-2 \sigma \phi}-2 e^{-\sigma \phi}}
$$

where $\sigma=0.4 \mathrm{~b} ; \quad \sigma_{244}=\sigma_{246}=\sigma ; \quad \sigma_{245}=2 \sigma ; \quad \sigma_{\mathrm{n}, 2 \mathrm{n}}=\sigma_{\mathrm{f}}=0 ; \quad \mathrm{N}^{244}$ $=\frac{s}{\sigma \phi}\left(1-e^{-\sigma \phi t}\right) ; \phi$ is thermal $(10 \mathrm{keV})$ flux. Figure 6 gives results of the approximate calculation. As can be seen from Table $I$, a significant improvement in thermal flux has been achieved. Concurrently with this, a factor of about 1000 decrease in yield has also taken place. Effects of 
this reduction in yield are most dramatically shown by a comparison of Fig. 7 which shows the "Mike" experiment results at the Bikini atoll and Fig. 8 which is an overview of a typical test area at the Nevada Test Site. Figure 9 shows a comparison of the element yields of one of the experiments with the Mike results.

Table I. Heavy-elements program experimental data.

\begin{tabular}{|c|c|c|c|c|c|}
\hline Sliul & $\begin{array}{l}\text { Sponsoring } \\
\text { Lábúiaturiy }\end{array}$ & Date & $R=\frac{A=246}{A=245}$ & $\begin{array}{l}\text { Implied t } \\
\text { (12meles }\end{array}$ & $\begin{array}{l}\text { hermal flux } \\
\left.12 / \operatorname{cm}^{2}\right)\end{array}$ \\
\hline Mike & LASL & $11 / 52$ & 0.38 & . & 2.0 \\
\hline Anacostia & LRL & $11 / 62$ & 0.48 & & 2.5 \\
\hline Kennebec & LRL & $6 / 63$ & 0.69 & & 4.7 \\
\hline Anchovy & LASL & $11 / 63$ & 0.4 & & 2.0 \\
\hline
\end{tabular}

As in any other development program, many problems remain. The extreme conditions existing in thermonuclear devices make it difficult to predict, with any degree of confidence, actual configurations and conditions. In addition, in a typical underground experiment at the Nevada Test Site, the reclaimed fraction of the device is of the order of $10^{-10}$. The fact that this fraction is so minute requires extremely sophisticated radiochemical techniques for the isolation and detection of new nuclides. Past experiments have served mainly to define relevant physical parameters; further experiments involving designs presently being studied both at. Los Alamos Scientific Laboratory and Lawrence Radiation Laboratory should be able to give considerably higher neutron exposures. 


\section{REFERENCES}

${ }^{1}$ S. A. E. Johansson, Nuclear Phys. 12, 449 (1959).

${ }^{2}$ L. Zamick and C. Y. Wong (private communication).

3. Perlman (private communication).

${ }^{4}$ B. Foreman and G. T. Seaborg, J. Inorg. and Nuclear Chem. 7 , 305 (1958).

${ }^{5}$ D. W. Dorn, Phys. Rev. 121, 1740 (1961).

${ }^{6}$ W. J. Whitehouse and W. Galbraith, Nature 169, 494 (1952).

${ }^{7}$ G. T. Seaborg, Phys. Rev. $\underline{85}, 157$ (1952).

${ }^{8}$ J. R. Huizenga, Phys. Rev. 94, 158 (1954).

${ }^{9}$ W. J. Swiatecki, Phys. Rev. 100, 937 (1955).

${ }^{10}$ A. Ghiorso, Proceedings of the International Conference on the Peaceful Uses of Atomic Energy, Geneva, 1955 (United Nations, New York, 1956), Vol. 7, Paper P/7.8.

${ }^{11}$ E. K. Hyde, University of California, Lawrence Radiation Laboratory Report UCRL-9036, 1960 (unpublished).

${ }^{12}$ F. G. Werner and J: A. Wheeler, Phys. Rev. 109, 126 (1958).

${ }^{13}$ R. Brandt, F. G. Werner, M. Wakano, R. Fuller, J. A. Wheeler, Proc. of International Conference on Nuclidic Masses, Hamilton, Ontario, University of Toronto Press, 94 (1960).

${ }^{14}$ D. W: Dorn, Phys. Rev. 126, 693 (1962).

${ }^{15}$ H. B. Levy, University of California, Lawrence Radiation Laboratory Report UCRL-4588, 1955 (unpublished).

${ }^{16}$ A. G. W. Cameron, Atomic Energy of Canada Limited, Chalk River Report CRP-690, 1957 (unpublished). 
${ }^{17}$ F. S. Mozer, Phys. Rev. 116, 970 (1959).

${ }^{18}$ P. A. Seegar, Nucl. Phys. 25, 1 (1961). 


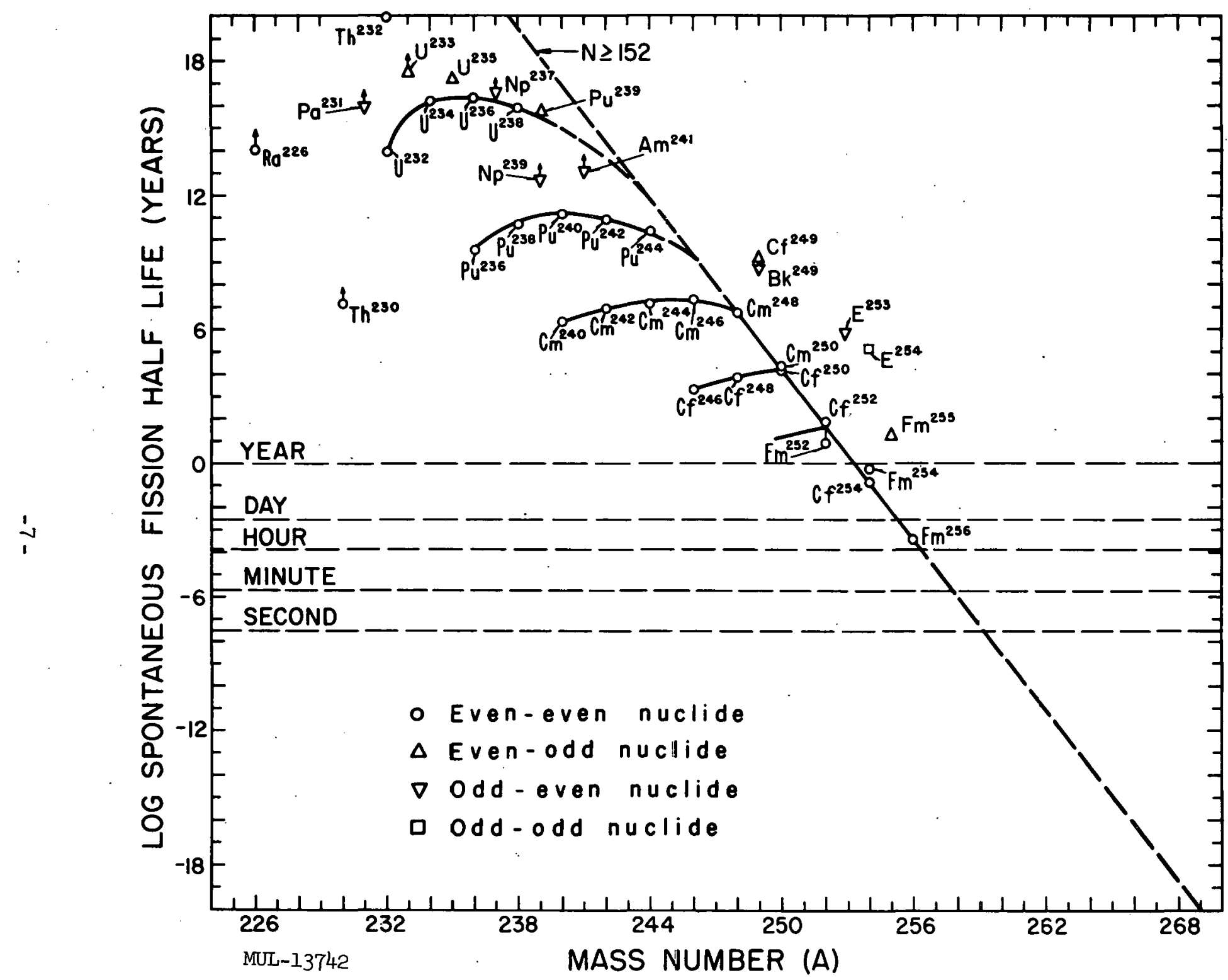

Fig. 1. Spontaneous fission half-lives as a function of mass number (from Foreman and Seaborg ${ }^{4}$ ). 


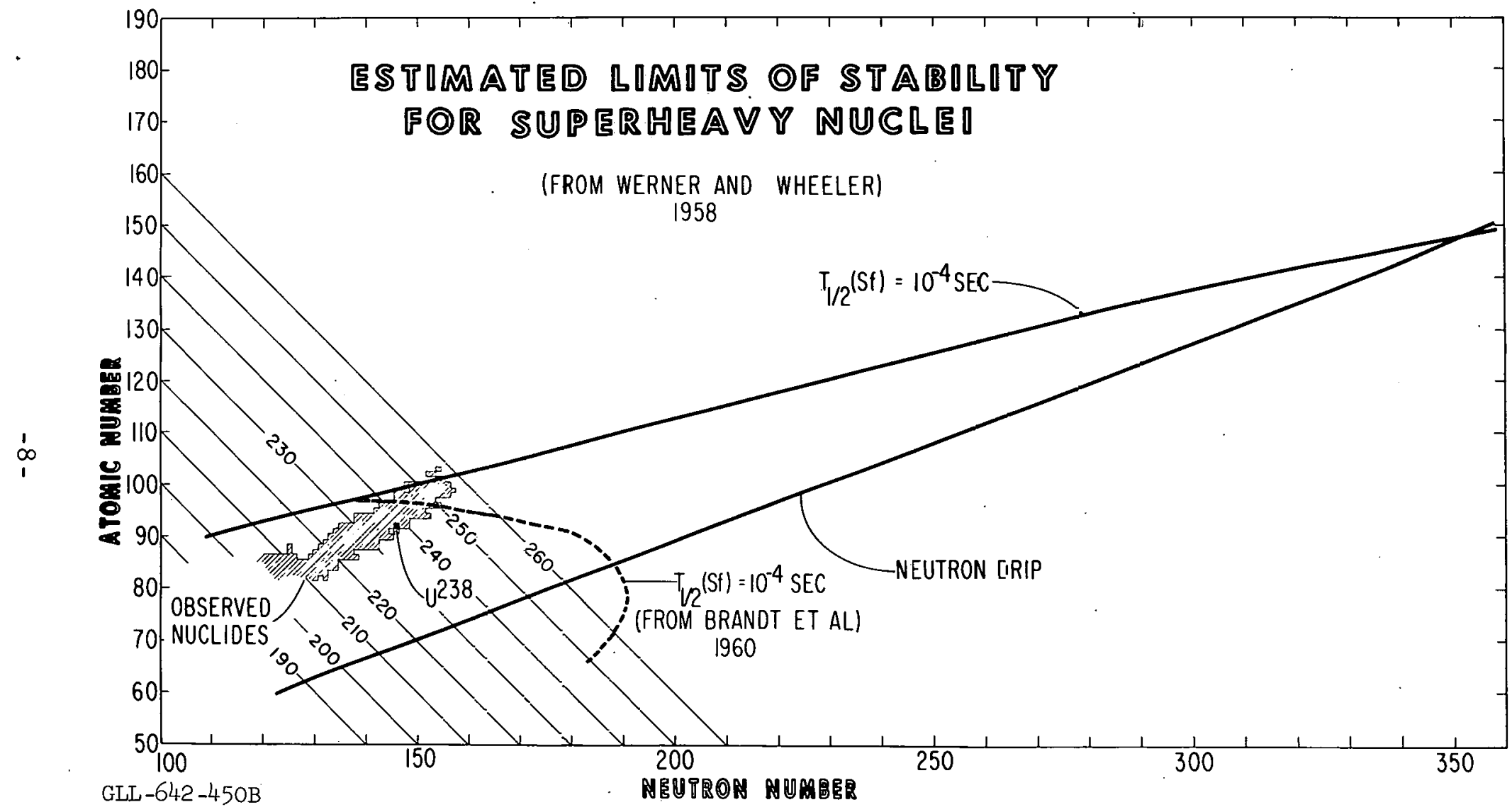

Fig. 2. Estimated limits of nuclear stability for superheavy nuclei (frcm Werner and Wheeler ${ }^{12}$ and from Brandt et al. ${ }^{13}$ ). 


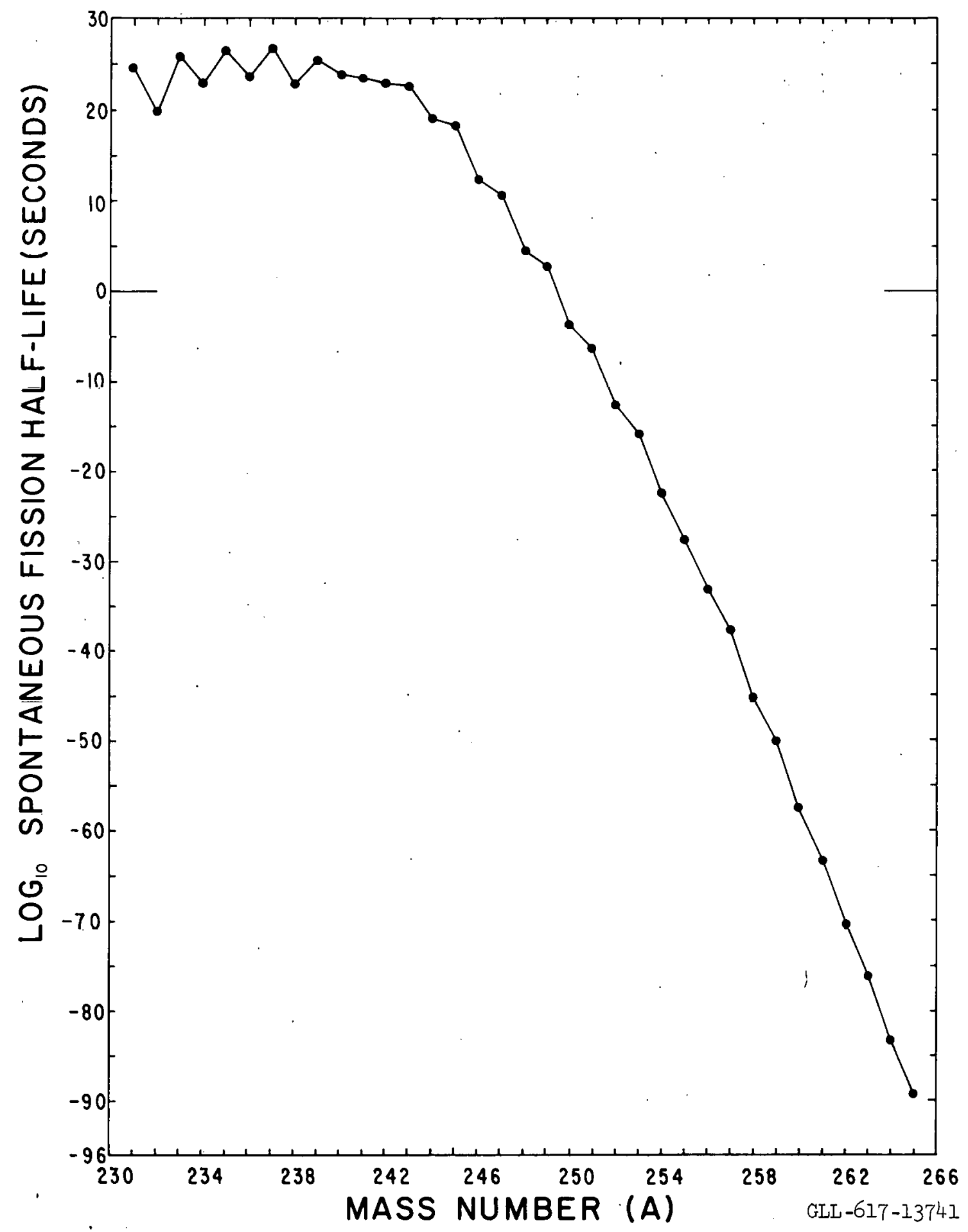

Fig. 3. Spontaneous fission half-lives for isotopes of uranium (from Dorn ${ }^{14}$ ). 


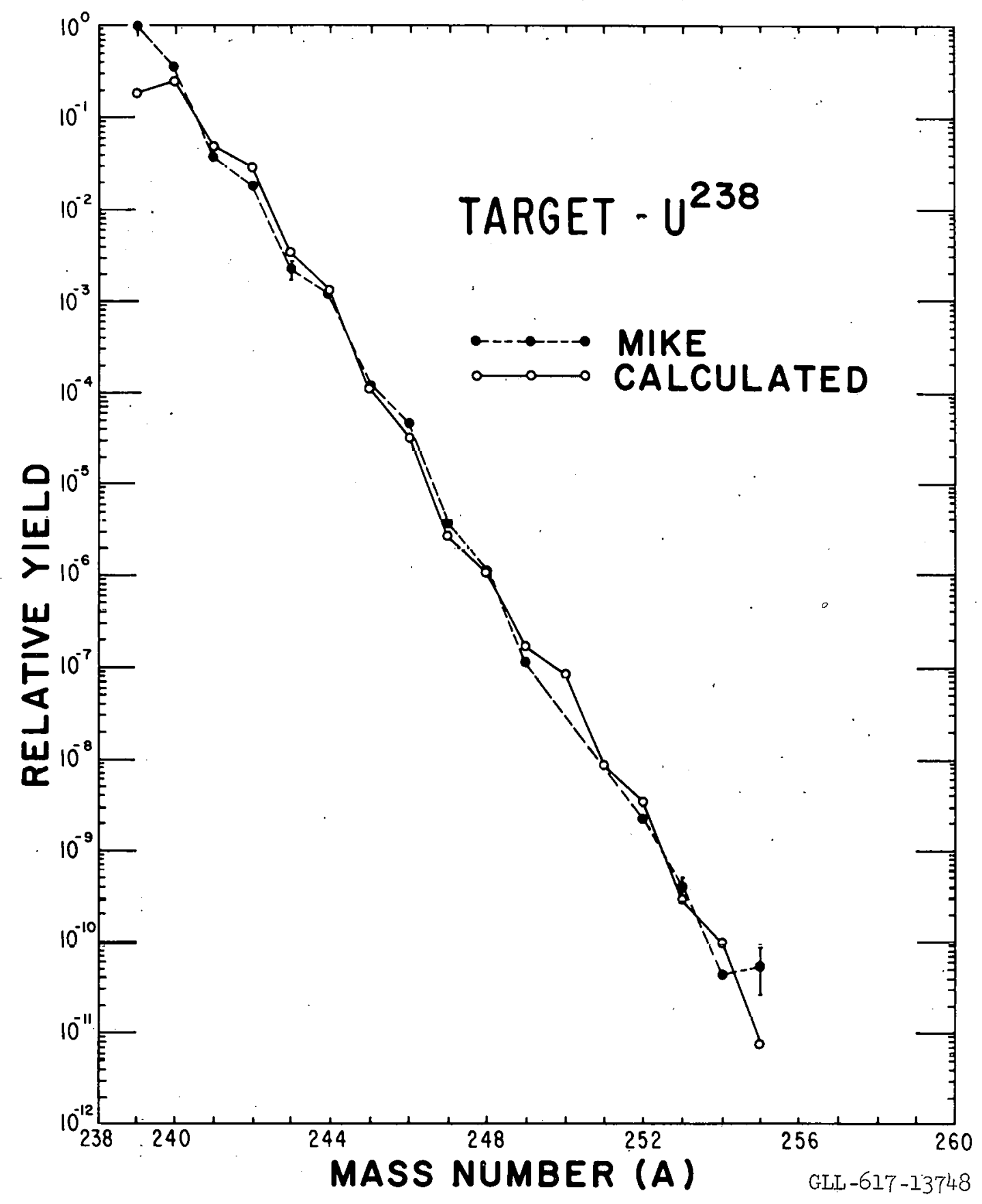

Fig. 4. Comparison of Mike heavy-element yields with the theoretical yields obtained assuming two flux regions $199.99 \%$ of the target at 2 moles $-n / \mathrm{cm}^{2}$ thermal flux and $0.01 \%$ at 8 moles $-\mathrm{n} / \mathrm{cm}^{2}$ ) and spontaneous fission half-lives as predicted by Dorn ${ }^{5}$ with the condition that $\mathrm{T}_{1 / 2}$ (spontaneous fission) $\geq$ $\mathrm{T}_{1 / 2}^{2}\left(\beta^{-}\right.$decay $)$. 


\section{MEAVY ELEMENT PRODUCTDON}

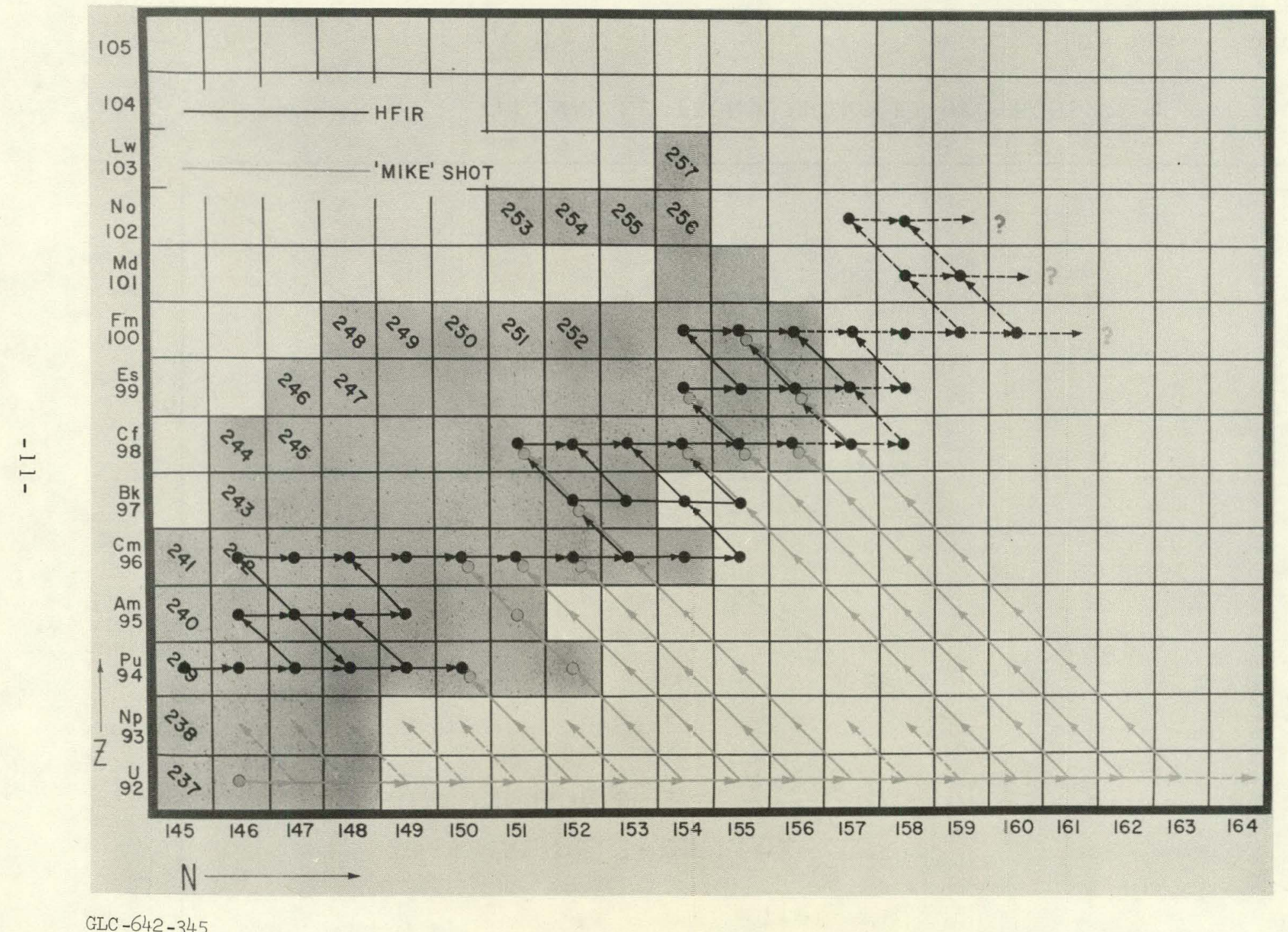

Fig. 5. Comparis on of capture paths followed in a reactor with those followed in a nuclear device. 


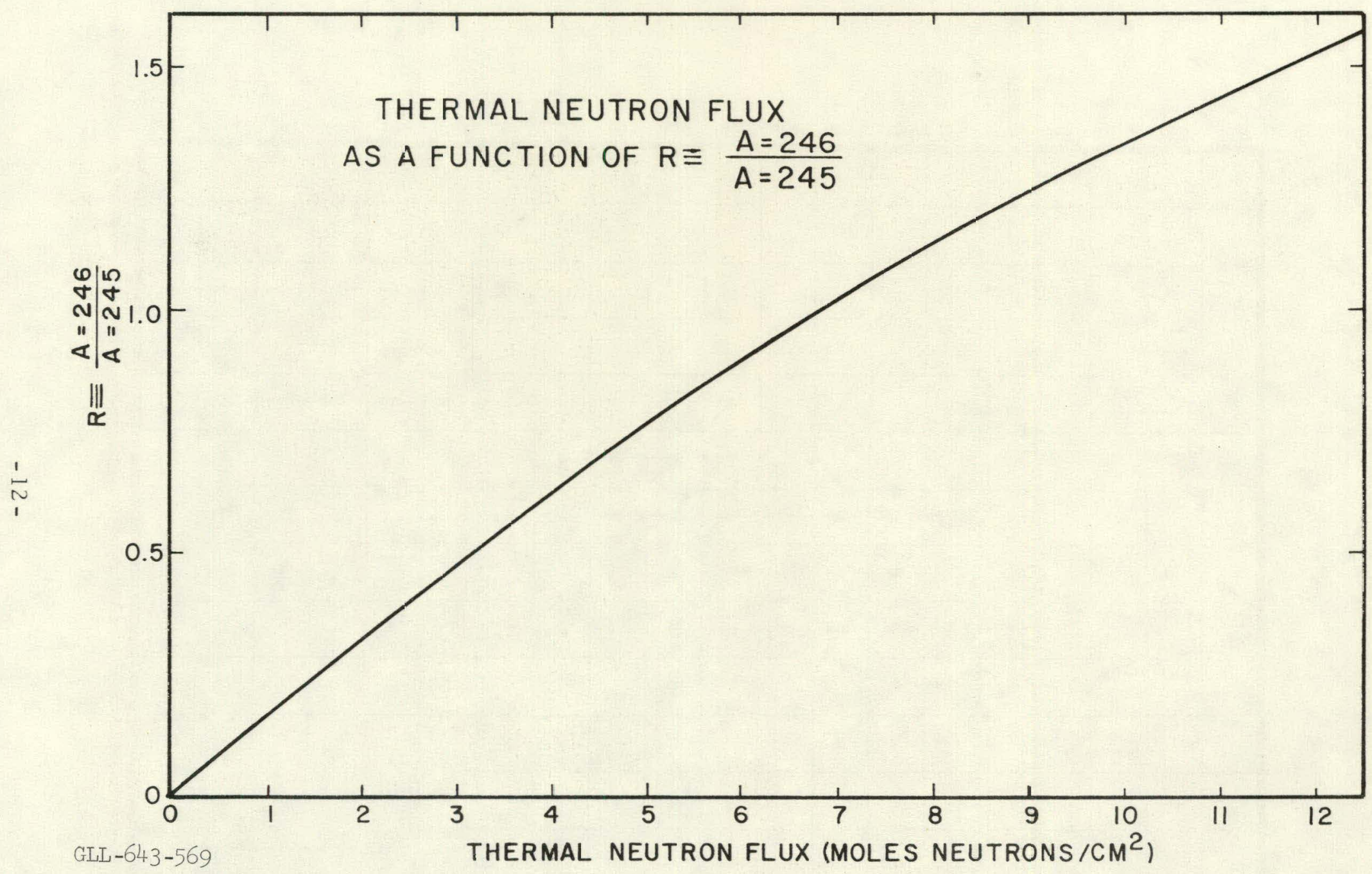

Fig. 6. Thermal neutron flux $(10 \mathrm{keV})$ as implied by the ratio of the amount of mass number 246 to that of 245 . 


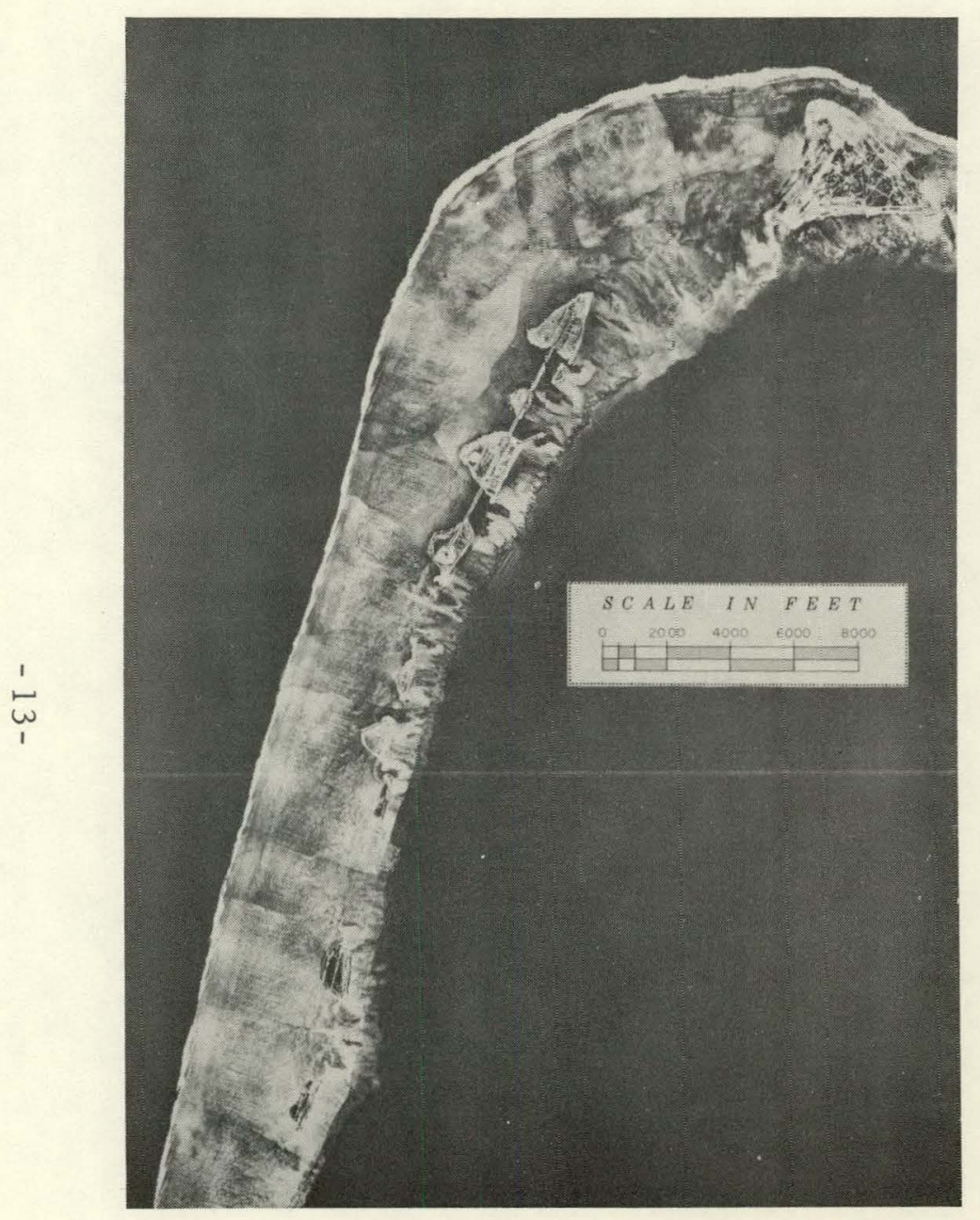

GLB $-611-23068$

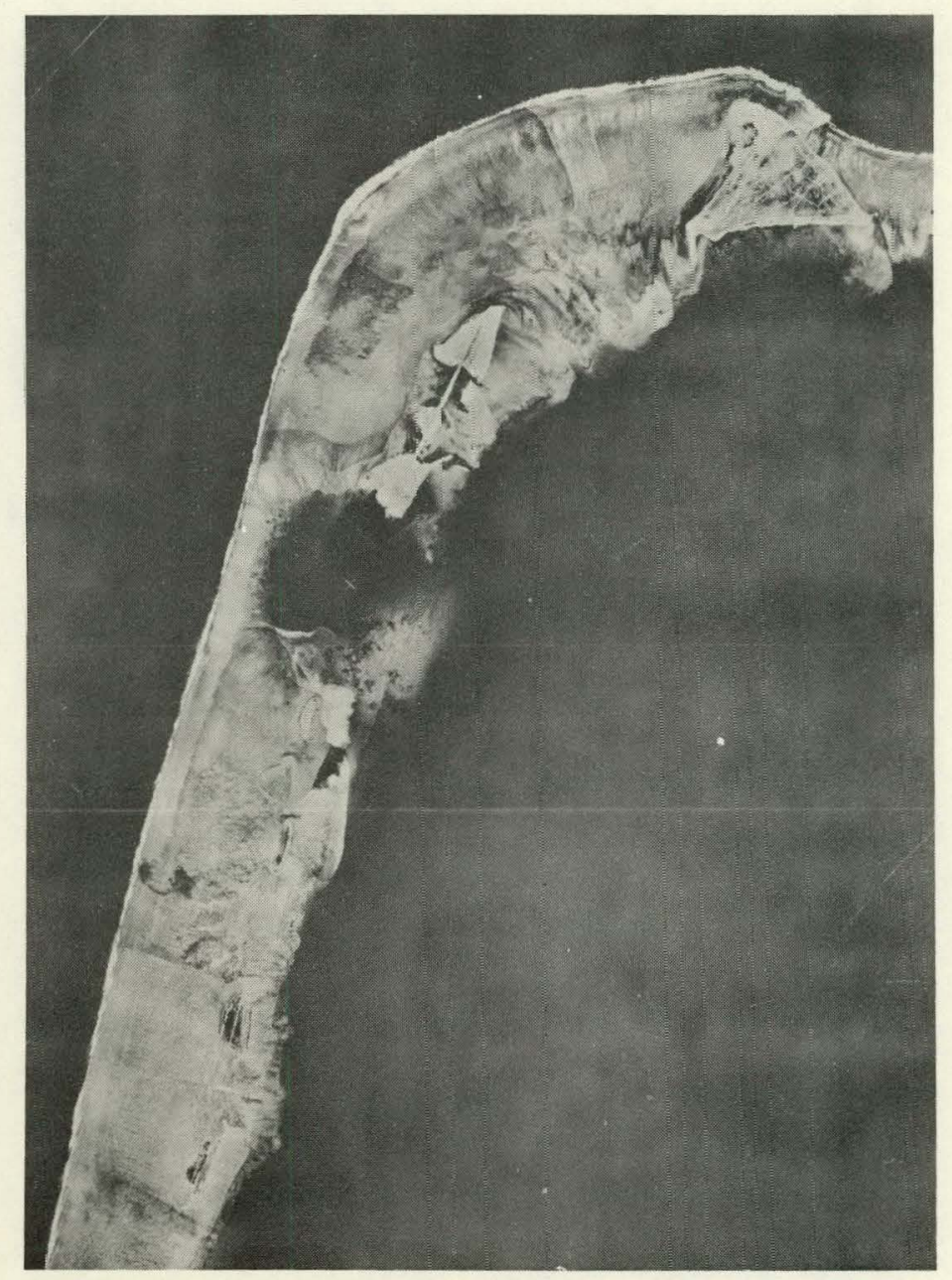

b

Fig. 7. Site of the 1952 thermonuclear experiment, Mike. 


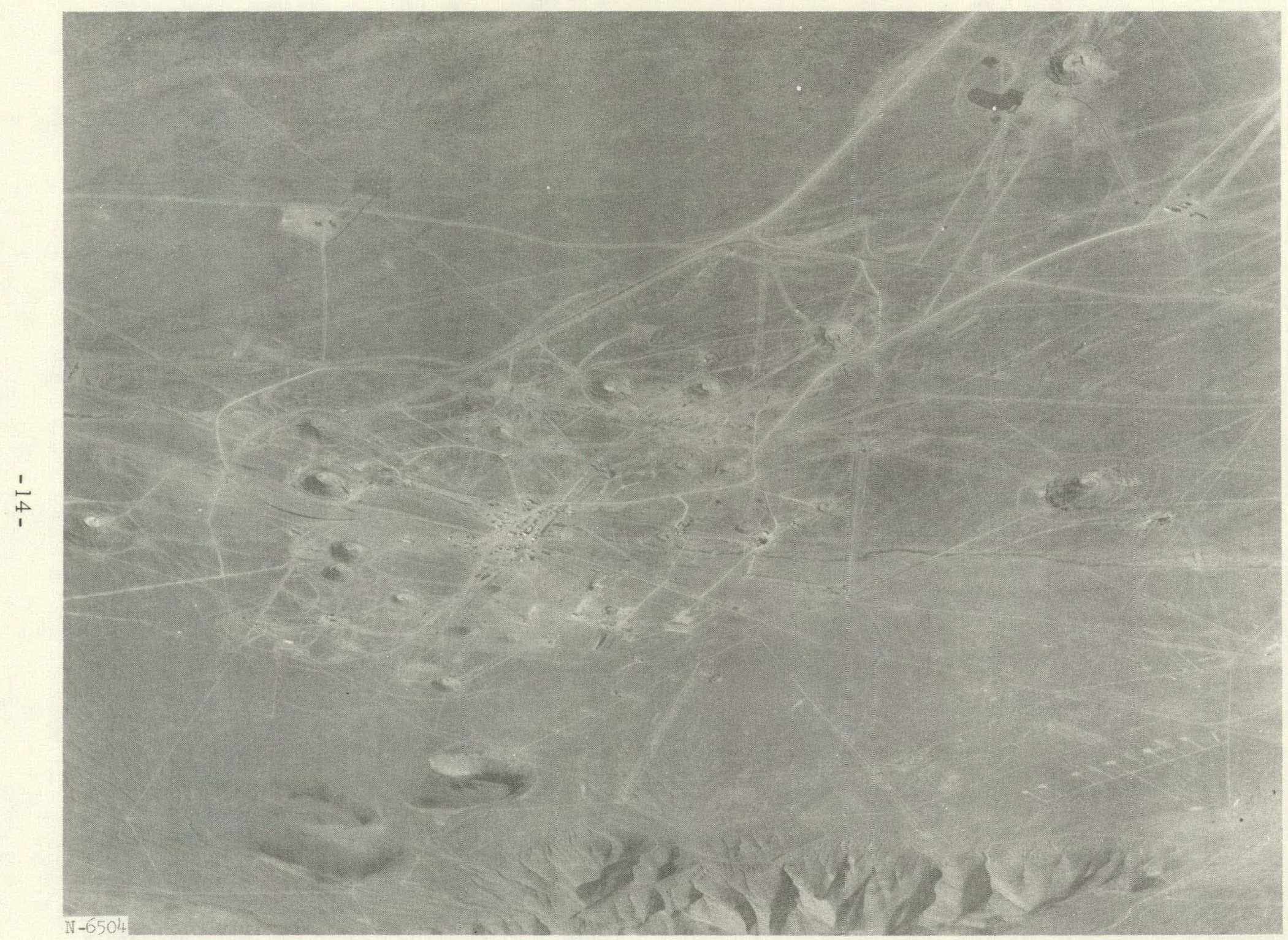

Fig. 8. Test area 9 at the Atomic Energy Commission's Nevada Test Site. 


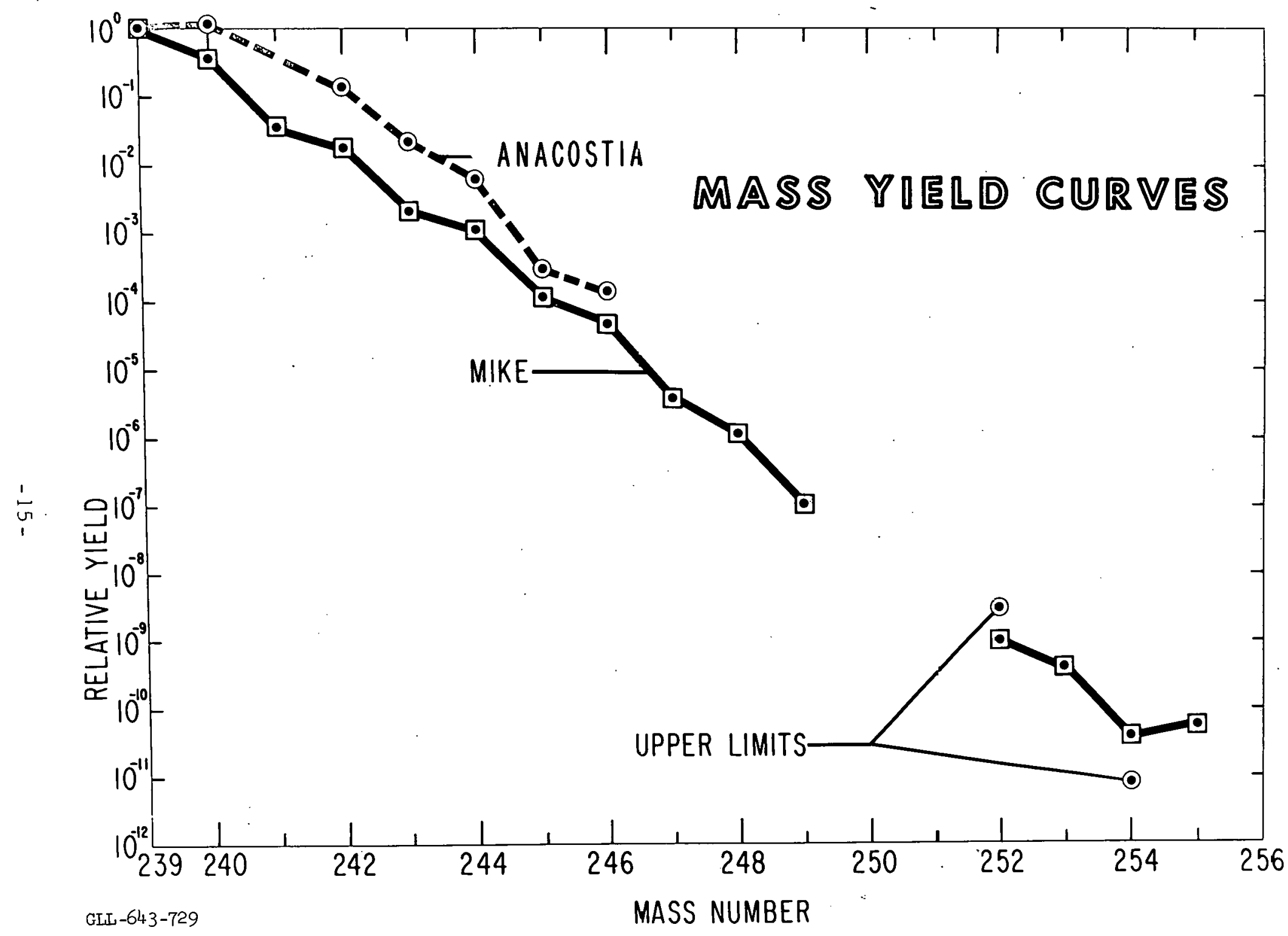

Fig. 9. Comparison of the element yields of the Anacostia experiment with Mike experiment. 
This report was prepared as an account of Government sponsored work. Neither the United States, nor the Commission, nor any person acting on behalf of the Commission:

A. Makes any warranty or representation, expressed or implied, with respect to the accuracy, completeness, or usefulness of the information contained in this report, or that the use of any information, apparatus, method, or process disclosed in this report may not infringe privately owned rights; or

B. Assumes any liabilities with respect to the use of, or for damages resulting from the use of any information, apparatus, method or process disclosed in this report.

As used in the above, "person acting on behalf of the Commission " includes any employee or contractor of the commission, or employee of such contractor, to the extent that such employee or contractor of the Commission, or employee of such contractor prepares, disseminates, or provides access to, any information pursuant to his employment or contract with the Commission, or his employment with such contractor. 